\title{
SCAR RUPTURE IN MID TRIMESTER ABORTION: A CASE SCENARIO
}

\author{
K. Indira Surya Kumari ${ }^{1}$, Lavanya Kumari Sarella²
}

\section{HOW TO CITE THIS ARTICLE:}

K. Indira Surya Kumari, Lavanya Kumari Sarella. "Scar Rupture in Mid Trimester Abortion: A Case Scenario". Journal of Evolution of Medical and Dental Sciences 2015; Vol. 4, Issue 07, January 22; Page: 1283-1284,

DOI: $10.14260 /$ jemds/2015/179

CASE REPORT: A 20yrs old G3,P1, L1, A1 with h/o previous cesarean section with 5months of amenorrhea presented to Government General Hospital, Kakinada, AP, India with bleeding PV and pain abdomen since 16 days. On enquiry it was found that she underwent medical termination of pregnancy 20 days back at a private hospital for five months of pregnancy followed by profuse bleeding per vagina and D\&E was done for the same complaint 16days back followed by intractable bleeding on table. She was transfused with one unit of blood and referred to Government General Hospital, Kakinada.

At the time of admission patient was pale with a BP $110 / 70 \mathrm{mmHg}$, pulse $76 / \mathrm{min}$ and afebrile. On examination suprapubic transverse scar was present with tenderness over suprapubic region. Uterus is around 14-16 weeks size. Per vaginal examination revealed opened cervical so with bleeding through os, uterus 14-16weeks size tender, mobile, fornices are free.

On Investigations her hemoglobin was $6 \mathrm{gm} \%$, with normal clotting profile. Sonography revealed retained products of conception and MRI showed a rent of about $2 \times 1 \mathrm{~cm}$ in the lower uterine segment with a low intense are suggestive of blood clot. 3units of compatible blood transfused. As there is no bleeding patient was discharged after observing for 10 days.

After 1 week patient came to hospital with bout of bleeding with pallor and BP 90/60mmHg and one unit of blood transfused. In view of recurrent bleeding episodes emergency laparotomy was planned.

On opening the peritoneum bladder was drawn up and densely adherent to lower uterine segment. Uterus contracted with ballooned out lower uterine segment. A rent of $2 \mathrm{~cm}$ found in the lower uterine segment. While dissecting the lower uterine segment bladder was injured and repaired with suprapubic cystostomy. On cut section around 500gms clots were present in lower uterine segment and cervical canal. Postoperative period was uneventful and patient discharged on $7^{\text {th }}$ postoperative day with supra pubic catheter in situ.

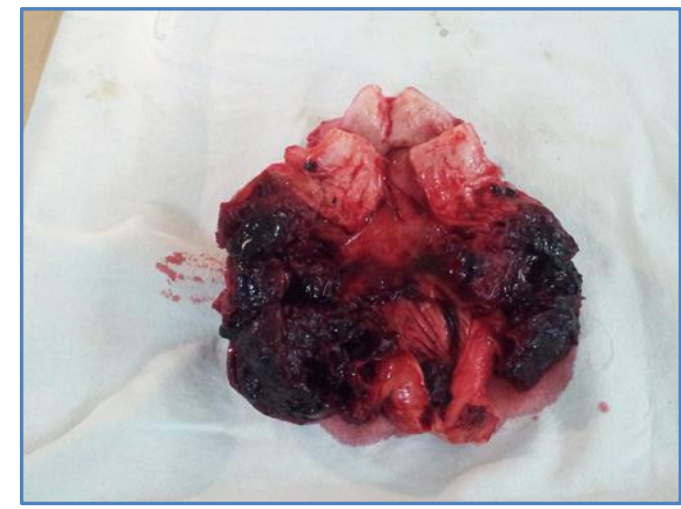

Cut section of uterus showing blood clot over scar rupture 
DISCUSSION: Uterine rupture is an uncommon, but a life-threatening complication following second trimester medical termination of pregnancy (TOP). The reported cases have been in both the scarred and unscarred uterus. The occurrence is about $0.2 \%$ in the intact uterus and 3.8 to $4.3 \%$ in the scarred uterus. The mortality and morbidity of the second trimester is greater than that of the first trimester termination. Abortion-related morbidity and mortality increase significantly as pregnancy advances with a sharp rise in the rate of severe complications in induced abortion after 14 weeks of pregnancy. Scar dehiscence, a less disruptive form of scar separation, has not been reported with dilation and evacuation abortion. Uterine scar dehiscence, a surreptitious process, can be the cause of hemorrhage after uncomplicated dilatation and evacuation ${ }^{1}$. The clinician dealing with second trimester terminations should be aware of the possibility of having a uterine rupture, especially in patients with a uterine scar in order to make an early diagnosis.

CONCLUSION: The rate of caesarean births has been on the rise, it has lead to and increasing numbers of women with a uterine scar seeking termination of pregnancy. Compared to complete uterine rupture uterine dehiscence has much lower maternal morbidity. The risk of uterine rupture has risen recently due increased rate of cesarean deliveries. ${ }^{2,3,4}$

\section{REFERENCES:}

1. Lichtenberg ES, Frederiksen MC. Cesarean scar dehiscence as a cause of hemorrhage after second trimester abortion by dilation and evacuation. Contraception. 2004; 70: 61-64. [PubMed]

2. Grobman WA, Lai Y, Landon MB et al. Prediction of uterine rupture associated with attempted vaginal birth after cesarean delivery. Am J Obstet Gynecol. 2008 Jul; 199 (1): 30.e1-5. doi: 10.1016/j.ajog.2008.03.039. Epub 2008 Apr 25.

3. Zwart JJ, Richters JM, Ory F et al. Severe maternal morbidity during pregnancy, delivery and puerperium in the Netherlands: a nationwide population-based study of 371, 000 pregnancies. BJOG. 2008 Jun; 115 (7): 842-50.

4. Guise JM, Eden K, Emeis C, Denman MA, Marshall N, Fu RR, Janik R, Nygren P, Walker M, Mc Donagh M. Evid Rep Technol Assess (Full Rep). 2010 Mar; (191): 1-397. Review. PMID: 20629481.[PubMed - indexed for MEDLINE].

AUTHORS:

1. K. Indira Surya Kumari

2. Lavanya Kumari Sarella

\section{PARTICULARS OF CONTRIBUTORS:}

1. Assistant Professor, Department of Obstetrics \& Gynaecology, Rangaraya Medical College, Kakinada.

2. I/C Professor, Department of Obstetrics \& Gynaecology, Rangaraya Medical College, Kakinada.

\section{NAME ADDRESS EMAIL ID OF THE} CORRESPONDING AUTHOR:

Dr. K. Indira Surya Kumari, Assistant Professor, Department of Obstetrics \& Gynecology, Rangaraya Medical College, Kakinada-533003, Andhra Pradesh. E-mail: drindirakothapalli61@gmail.com

Date of Submission: 28/12/2014. Date of Peer Review: 29/12/2014. Date of Acceptance: 13/01/2015. Date of Publishing: 22/01/2015. 